\title{
Why is it hard to solve environmental problems? The perils of institutional reductionism and institutional overload
}

\author{
Oran R. Young ${ }^{1} \cdot$ Olav Schram Stokke ${ }^{2}$ (D)
}

Accepted: 16 January 2020 / Published online: 27 January 2020

(c) The Author(s) 2020

\begin{abstract}
Many efforts to solve environmental problems arising at the international or transnational level meet with limited success or even end in outright failure. But some efforts of this sort succeed. We construct an analytical model of such efforts leading to the conclusion that an ability to steer a course that avoids the twin perils of institutional reductionism and institutional overload is necessary to achieve success in this realm. We examine a range of risk factors or conditions likely to push processes of regime formation and implementation into one or the other of these pitfalls. We then analyze response strategies or procedures that negotiators and administrators can adopt to steer a course between the two perils, taking into account distinctive features of specific problems. We turn to marine issues to illustrate our reasoning. But the argument is applicable to the entire range of efforts to create and implement international environmental regimes.
\end{abstract}

Keywords International regimes · Institutional overload · Institutional reductionism · Risk factors $\cdot$ Response strategies

\section{Sources of institutional success and failure}

Efforts to create governance systems or, as we often say, regimes to address international or transboundary environmental problems often produce results whose contributions to problem solving are limited or that even end in outright failure. Yet some regimes (e.g., the regime dealing with ozone-depleting substances) are widely regarded as successes. The evidence supporting these propositions about success or effectiveness (Young 2011) includes both qualitative accounts (Speth 2004; Park et al. 2008; Hale et al. 2013) and quantitative analyses (Miles et al. 2002; Breitmeier et al. 2006, 2011). What makes it so hard to achieve success in this realm? How can we make progress in identifying major causes of failure and pinpointing conditions required to achieve success in solving (or at least alleviating) a variety of environmental problems?

Oran R. Young

oran.young@gmail.com

1 Bren School of Environmental Science and Management, University of California at Santa Barbara, Santa Barbara, CA 93106-5131, USA

2 Department of Political Science, University of Oslo, Oslo, Norway 
In this article, we develop an analytical model to address these questions. Starting with a discussion of the meaning of success and failure, we proceed to construct an integrated account dealing with some key factors that can undermine efforts to create successful governance systems. Our core argument is that finding ways to overcome the pitfalls associated with the twin perils of institutional reductionism and institutional overload is necessary for the achievement of success. We do not have quantitative data that would allow for systematic empirical testing of the implications of this model. But we provide examples to illustrate our principal arguments, and we cast our main conclusions as hypotheses regarding necessary conditions for success that future research can test empirically through the development of in-depth case studies and quantitative analyses drawing on larger numbers of cases.

We treat success as a matter of solving (or at least alleviating substantially) the problems leading to the creation of environmental governance systems (Young and Levy 1999). Are severely depleted fish stocks recovering? Are we phasing out the production and consumption of ozone-depleting substances? Can we avoid dangerous anthropogenic interference in the Earth's climate system? Approached in this way, failure can take several distinct forms. In the extreme, negotiators are simply unable to reach closure on the terms of any agreement addressing the relevant problem that is acceptable to all the parties. Short of this, failure can take the forms of stillborn regimes, defective agreements, dead letters, or regimes lacking in adaptive capacity. Stillborn regimes are arrangements that fail to enter into force or do not make a transition from paper to practice, even if they enter into force formally (Mitchell 1994). Regardless of how attractive they may look on paper, such regimes cannot solve the problem(s) leading to their creation. Defective agreements fail to include provisions needed to tackle the core issues involved or are afflicted with debilitating internal contradictions, even though they are cast in the form of legally binding instruments or formal agreements. Situations of this kind are frequent outcomes of hard bargaining resulting in debilitating compromises regarding the terms of agreements dealing with international or transboundary environmental issues (Young 1994). Dead letters are regimes that fail to make a significant difference in terms of problem solving, despite the fact that they do make an initial transition from paper to practice. Gradually, they fade into the background, remaining in place formally but failing to produce significant results in terms of influencing the behavior of those whose actions have given rise to the relevant problem(s). Finally, regimes lacking in adaptive capacity are apt to fail as means of addressing problems that are dynamic in character. In effect, they become obsolete as the character of the problem(s) evolves over time without triggering the necessary institutional adjustments (Young 2017a).

Success and failure do not constitute a sharp dichotomy. They involve a continuum, ranging from resounding success to outright failure. Governance systems may make some difference even in cases where the problem does not go away (Breitmeier et al. 2011). Though it is hard to construct convincing counterfactuals, there are certainly cases where the problem would have gotten worse in the absence of a regime created to address the problem. Nevertheless, success in creating regimes to address international or transboundary environmental problems is elusive. Arrangements that produce disappointing results are common.

Institutional reductionism arises from efforts to strip away much of the complexity of real-world situations, simplifying the agenda and highlighting key issues as a means of improving the prospects of concluding negotiations successfully. If carried too far, reductionism produces agreement on arrangements that do not take into account important aspects of the problem at hand. As a result, they fail to deliver on one or 
more of the core tasks of environmental governance relating to knowledge production, regulation, and behavioral adaptation (Stokke 2012). Institutional overload, by contrast, arises from enlarging the group of players or expanding the range and complexity of the issues included in the negotiations in order to take into account the full range of concerns involved. If carried too far, overload results in complex arrangements that may seem attractive in principle but are too convoluted to serve as effective steering mechanisms under real-world conditions. Reductionism and overload are opposing pitfalls, occupying opposite ends of a single continuum. Going to extremes to avoid one peril will cause negotiators and administrators to fall prey to the other. Creating environmental governance systems that can solve (or substantially alleviate) problems requires the ability to find a middle way, steering a course that avoids falling into one or the other of these traps.

In the substantive sections of this article, we begin with an analysis of the twin perils, first probing the nature of institutional reductionism and then examining institutional overload. This provides a basis for the analysis of what we call risk factors or conditions that tend to push efforts to create or implement governance systems toward reductionism or overload, even in cases where there are experienced participants familiar with the processes involved in negotiating international environmental agreements. We examine risk factors relating to the character of the problem, institutional design, and the broader setting within which negotiations take place and regimes operate. In each case, we look for forces that, despite the best intentions of the participants, can push efforts to create and operate governance systems toward the pitfalls of reductionism or overload. We then consider response strategies treated as measures designed to steer a course between the twin perils. In each case, devising a response strategy that works constitutes a necessary condition for success; regimes that fail to meet this test cannot succeed in solving the problem(s) leading to their creation. Space limitations make it necessary to limit our analysis to a few risk factors and response strategies relevant to institutional success and failure. Still, we believe the factors and responses we do consider are among those most relevant to institutional success or failure.

\section{Twin perils: reductionism and overload}

Both institutional bargaining and the implementation of the resultant regimes feature dynamics that individual participants are unable to manage or control on their own (Young 1994). Those negotiating the terms of new or restructured regimes must walk a fine line between the pursuit of divergent interests centered on maximizing their individual gains and respect for common interests in achieving Pareto optimal outcomesoutcomes that all participants prefer to an outcome of no agreement. They must learn the art of navigating in the realm of "mixed-motive interactions" (Schelling 1960), producing coherent results rather than contradictory provisions or vague formulas designed to paper over serious disagreements (Brennan and Buchanan 1985). Much the same is true of the efforts of those responsible for operating governance systems once they are put in place. Common pitfalls in such processes, which can trap even the most experienced negotiators, take the forms of reductionism and overload. 


\subsection{The peril of reductionism}

Institutional reductionism refers to processes in which (1) actors strip away potentially relevant features of a problem generating a need for governance by making ceteris paribus assumptions or using similar procedures designed to abstract away or hold constant various factors for purposes of regime formation; and (2) negotiators design regimes that seem appropriate for addressing the simplified problems remaining, but that commonly produce disappointing results when applied to real-world situations (Young 2008; Young et al. 2018).

From the perspective of problem solving, the peril of institutional reductionism amounts to simplification that is taken too far. Reduction may range from extreme simplification to more limited efforts to abstract away a few seemingly peripheral matters in order to highlight the central features of the problem producing a need for governance. Consider some examples relating to fisheries management. In the extreme, actors focus on the management of a single fish stock located in a stable ecosystem lying wholly within a single jurisdiction and with a single objective (e.g., maximum sustainable yield or MSY) to be met. Even here, there is room for lively debate. Differences in the assessments of analysts like Hilborn (2012) and Pauly (2010) regarding the extent to which a fish stock can be reduced without jeopardizing sustainable yields are well-known examples, and fishers employing different gear types may hold competing positions on how to allocate the allowable harvest level. But once agreement is reached on the operational meaning of MSY for the stock and how to divide it among vessel groups, governance becomes a matter of establishing mechanisms to adjust allowable harvest levels, limit fishing effort accordingly, and monitor the status of the stock, occasionally making suitable adjustments.

The simplification or narrowness inherent in such practices becomes apparent whenever one or more of the following considerations acquire political saliency:

1. Environmental connectedness: interactions between two or more species introduce new management challenges, especially when different vessel groups value these species differently.

2. Broader objectives: there are compelling reasons to shift from pursuit of MSY, which is a biophysical criterion, to maximum economic yield (MEY) or even optimum sustainable yield, as required in the US Fishery Conservation and Management Act, which stipulates that optimum sustainable yield is MSY "as modified by any relevant economic, social, or ecological factor" (FCMA 1976).

3. More actors: jurisdictional complexity is compounded as a fish stock expands into yet another Exclusive Economic Zone (EEZ) or straddles a boundary that separates an EEZ from the high seas.

4. A wider range of issues: harvesting operations have severe unintended consequences in such forms as by-catches of other fish species or marine mammals or impacts on other marine systems (e.g., coral reefs) or other human activities (e.g., shipping, oil or gas extraction, recreational activities) within the same space/time coordinates.

Dealing with each of these concerns requires institutional arrangements that go well beyond the simple problem of achieving MSY from a single stock. In the case of a fish stock straddling jurisdictional boundaries, for instance, an existing intergovernmental arrangement (e.g., a regional fisheries management organization) may need to expand to include new members. In situations involving multiple uses, it may be necessary to 
create procedures for resolving interactions among two or more regimes dealing with distinct human activities (Oberthür and Stokke 2011). In cases where ecosystem services are important (MEA 2005; IPBES 2019), it may make sense to establish marine protected areas.

Relaxing our simplifying assumptions further, we can acknowledge that most fish stocks of interest are embedded in larger ecosystems, and begin to think in terms of ecosystem-based management or EBM (McLeod et al. 2009). This raises important biophysical questions, such as whether other forces in the ecosystem affect the population dynamics of a targeted fish stock or whether changes in the abundance of a targeted stock will have knock-on effects on the ecosystem. This is where the current debate about the connections between the establishment of marine protected areas (MPAs) and the management of commercial fisheries enters the picture. Moving to EBM also introduces new evaluation criteria for ecosystem services that go well beyond the value of commercial harvests of the targeted species. This is especially challenging when some of these criteria involve services or other human activities (e.g., sport and recreational fishing, scuba diving, sightseeing) whose value is difficult to calculate in conventional utilitarian terms.

Beyond this lies the domain of broader systemic forces that may have profound consequences for the status of the individual fish stock in question. Prominent among these forces are (1) climate change, including shifts in water temperatures, salinity, prevailing currents, the presence of sea ice, and ocean acidification, (2) the diffusion of pollutants (like plastics) that affect the health of marine systems, and (3) the growth of hypoxic or dead zones arising from uses of fertilizers and pesticides in remote agricultural operations. Broadening the scope of the analysis to consider these dimensions obviously complicates efforts to address the governance challenges associated with fisheries management. However, governance systems that fail to recognize such concerns are likely to experience major surprises that are generally unpredictable but often nasty from the perspective of problem solving.

Some measure of institutional simplification, or narrowness in terms of issues considered and actors involved, is unavoidable. It would be unrealistic, for example, to expect those negotiating the terms of a regional fisheries management organization to take responsibility for tackling problems like climate change or the spread of plastic debris in the world's oceans. On the other hand, it is not unreasonable to expect negotiators to be aware of such matters and to create institutional arrangements that can operate effectively in the face of such broader concerns, or at least include mechanisms for adjusting their provisions in a manner responsive to changes in broader conditions. The key challenge is to determine what degree of institutional simplification is appropriate in specific cases. Dealing with reductionism involves determining when the benefits of expanding the scope of the issues and actors covered are offset by the costs of doing so, measured in terms of reduced probability of reaching agreement on the terms of a coherent and effective regime to address the problem at hand. There is no simple algorithm for making such calculations. Decisions about such matters necessarily involve judgments on the part of those responsible for handling specific cases. There is much to be said for encouraging cooperation between analysts who understand the dynamics of the systems involved and practitioners with expertise in framing issues to maximize the prospects of completing negotiations successfully. Despite the best efforts of analysts and practitioners, judgments about such matters made in specific cases may prove faulty. But we should strive to make decisions based on the best available knowledge and to be open to revising these decisions as new evidence becomes available. 


\subsection{The peril of overload}

Institutional overload, the twin peril, occurs when negotiators expand the scope or complexity of institutional bargaining to the point where it is difficult or impossible to reach agreement on the provisions of a coherent regime, much less a governance system that can steer the actions of relevant players effectively once the regime makes the transition from paper to practice (Birch 1984). Like reductionism, overload is a variable: Increases in scope and complexity may range from limited adjustments needed to circumvent the peril of reductionism to expansions in processes of institutional bargaining that make it impossible for negotiators to achieve institutional success or to the creation of arrangements that are too complex to administer successfully.

In our example relating to fisheries management, the dangers of overload become apparent whenever one or more of the following conditions shapes the course of institutional bargaining:

1. Environmental connectedness: incorporation of multiple-species considerations increases the level of uncertainty and the potential for politicization of scientific understanding regarding how any given level of harvesting will affect the ability of stocks to replenish themselves.

2. Broader objectives: attention to a wider set of societal objectives produces regimes that seek to maximize two or more distinct goals (e.g., efficiency, employment in coastal communities, and distributive justice) in situations where there is no straightforward way to arrive at trade-offs between or among them.

3. More actors: inclusion of additional actors undermines arrangements for allocating benefits or introduces new jurisdictional complications.

4. A wider range of issues: expansion of the agenda to address side-effects and multiple-use tensions introduces additional issues that are only loosely connected to the harvesting activity.

Taking steps to increase the scope of negotiations is not always a bad idea. Some analysts have introduced the idea of negotiation arithmetic in thinking about such matters (Sebenius 1984). They observe that adding or subtracting issues or actors can help to make institutional bargaining tractable in some contexts. In legislative situations, this gives rise to processes of "log-rolling" in which differences in the intensity of the interests of key players across issues allow participants to build effective coalitions by trading votes on different issues to mutual advantage. In negotiations focused on the establishment or reform of environmental regimes, analogous processes feature the emergence of negotiating groups or blocs that are able to make mutually advantageous trades using the currency of language to be included in the articles of a convention, treaty, or other legally binding instrument.

To illustrate the deliberate expansion of the scope of issues for purposes of promoting cooperation, consider UN General Assembly Resolution 72/249, which launched an Intergovernmental Conference on Marine Biodiversity of Areas Beyond National Jurisdiction (BBNJ) and instructed the conference to begin work on crafting the provisions of an international legally binding instrument dealing with a specific set of issues relating to BBNJ (UNGA 2017). Expected to take the form of an implementation agreement nested within the framework of UNCLOS, the BBNJ agreement would cover four distinct sets of topics: (1) marine genetic resources, (2) area-based management tools, (3) environmental impact 
assessment procedures, and (4) capacity building and technology transfer. There is much to indicate that inclusion of the fourth topic was important in order to gain support from a set of developing countries that had voiced concerns about the costs of meeting their commitment under a BBNJ agreement. But the real question is whether it is realistic to expect negotiators to produce a coherent outcome addressing this whole suite of issues.

With respect to actor inclusiveness, the recent negotiations relating to fisheries in the Central Arctic Ocean provide a striking example. The five coastal states initially sought to limit the negotiations to themselves, but soon found that this grouping was not sufficient to address the problem effectively (Stokke 2016). The second round of negotiations was expanded to include China, Iceland, Japan, Korea, and the European Union. The negotiators made a point of excluding others, expecting the $5+5$ formula to prove tractable in terms of institutional bargaining and sufficient in terms of inclusiveness to address the problem effectively.

It is difficult to arrive at any simple formula regarding the treatment of these matters in specific cases of institutional bargaining. Nevertheless, institutional overload looms as an increasingly dangerous peril as those responsible for creating or implementing a regime move toward expanded scope or increased complexity in terms of each of the key dimensions. As in the case of institutional reductionism, the consequences of overload may range from situations in which greater scope or increased complexity facilitates coalition building to situations in which the parties are unable to arrive at any agreement acceptable to all. While stalemate may reflect unwillingness on the part of key players to compromise on a single divisive issue, it commonly occurs in situations where the scope of the negotiations becomes too broad and complex to allow for coherent outcomes. Defined in this way, the peril of overload becomes increasingly severe when negotiators take matters of scope and complexity too far, impeding efforts to address needs for governance effectively instead of promoting efforts to solve specific problems.

Each of these steps, deriving from the inclusion of expanded sets of issues and actors in an institutional arrangement, the broadening of the spatial coverage of new institutions, or the adoption of provisions that seem attractive on paper but are difficult to implement, adds to the challenge of producing governance systems that can solve environmental problems. It is not easy to devise principles to allow negotiators to optimize in terms of these dimensions, and there is no shortage of cases in which negotiations have ended in stalemate (e.g., the 2009 Conference of the Parties to the Climate Convention), produced outcomes that failed to enter into force (e.g., the 1988 Antarctic Minerals Convention), or yielded results whose performance is disappointing in terms of problem solving (e.g., the 2001 Stockholm Convention on Persistent Organic Pollutants). Overload, like its reductionist twin, constitutes a peril that can push unwary negotiators or administrators into situations resulting in institutional failure.

\section{Risk factors and response strategies}

The perils of institutional reductionism and institutional overload can wreak havoc with efforts to create regimes capable of solving environmental problems, even in cases where negotiators and administrators are aware of and understand the dangers associated with these perils in general terms. This makes it important to identify factors-we call them risk factors-likely to propel governance systems toward one or the other of the perils and to consider response strategies that can help negotiators and administrators to avoid the 
consequences of reductionism and overload in specific cases. How is it that negotiations can slide into extreme simplification or fall prey to excessive complexity, without anyone sounding the alarm or taking effective steps to prevent movement along the slippery slopes of reductionism or overload? Are there forces endemic to institutional bargaining or to the implementation of regimes that push participants in one direction or the other in a way that is difficult to anticipate, challenging to monitor, or hard to counter effectively in a world of actors motivated primarily by self-interest? Are there procedures-we call them response strategies - that can help participants in such processes to find middle ways that are helpful in avoiding these perils, without compromising their bargaining strength or administrative capacity in ways that limit their ability to maximize individual gains?

Risk factors of this sort are abundant. We are not able to offer a formal taxonomy identifying these factors in a mutually exclusive and exhaustive fashion. But for purposes of analysis, we find it helpful to group risk factors into three familiar categories: conditions relating to the character of the problem (e.g., malignancy, complexity, dynamism, uncertainty), matters of institutional design (e.g., decision rules, substantive provisions, liability rules), and features of the broader setting (e.g., political context, socioeconomic environment, cognitive setting).

In this short paper, we cannot analyze the full range of risk factors. Instead, we select one risk factor relating to each of the three categories, exploring the nature of the risk and the mechanisms through which it can lead to results that run afoul of the peril of reductionism or the peril of overload. We also offer a preliminary assessment of response strategies in each of the three cases that can prove helpful to those seeking to steer a course that minimizes the dangers of falling into the pitfalls associated with the twin perils. Our conclusion is that further research should focus on identifying risk factors in greater detail and testing the hypothesis that in each case the development of an effective response strategy constitutes a necessary condition for success in solving environmental problems. For those interested in applications, a focus on the development of response strategies will become a priority.

\subsection{Complexity}

Complexity is a measure of the extent to which a problem is linked to an array of issues extending beyond the core concern (Underdal 2010). In the case of fisheries, for example, there are questions regarding whether the relevant fish stocks are affected by developments such as increases in the temperature of the water column or runoffs of nutrients or other land-based marine pollutants causing the spread of dead zones. Fishing operations can themselves be a significant driver of certain environmental problems, such as the destruction of benthic communities or coral reefs. In biophysical terms, problems may be more or less self-contained with regard to their links to broader systems, and those broader systems may be more or less complex in terms of factors like hyperconnectivity, nonlinearity, directional change, and the prevalence of unexpected developments arising as emergent properties (Young 2017a, b). Highly complex biophysical systems place special demands on international governance arrangements when the activities relevant to problem solving fall under the jurisdiction of different sectors of government.

Humans are accustomed to thinking in terms of systems that are relatively simple. The reductionist inclination is to seek to encapsulate each of these problems in the interests of making negotiations and administrative procedures tractable. Pressure toward reductionism is likely to be reinforced if existing institutions place regulatory authority over ecosystem 
components in separate arrangements involving different sectors of government. Such separation is common in ocean management because many international fisheries institutions were established well before regimes for marine environmental protection arose. For instance, the fact that the pre-existing North-East Atlantic Fisheries Commission (NEAFC) already possessed management authority over high-seas harvesting operations goes a long way toward explaining why the mandate of the OSPAR Commission for the Protection of the Marine Environment of the North-East Atlantic excludes "questions relating to the management of fisheries" (OSPAR Convention, Preamble and Article 4). Such savings clauses, protecting commitments already entered into in previous agreements, are common in international environmental diplomacy (van Asselt 2011) and often promote institutional reductionism. Another example is the provision in UNGA Resolution 72/249 setting forth the mandate of the BBNJ negotiations stating that the "process and its results should not undermine existing relevant legal instruments and frameworks and relevant global, regional and sectoral bodies" (UNGA 2017). Yet it is apparent that any new arrangement capable of making a difference with respect to biodiversity beyond national jurisdiction will have significant implications for existing regimes dealing with marine fisheries, commercial shipping, deep seabed mining, and (potentially) certain aspects of oil and gas development.

Illustrating the peril of reductionism, NEAFC's response when alerted by the OSPAR Commission to the need to protect rare and threatened cold-water coral reefs from the effects of bottom trawling was to point out that international measures constraining fisheries operations were an exclusive NEAFC competence and that aggregation with environmental-protection interests should be dealt with at the national level (Kvalvik 2012). This defensive approach increased the risk that measures taken under the two regimes, involving largely the same set of states, would be incoherent with respect to area protection. It also implied that the regional institution with greatest expertise in defining and applying criteria for area protection would not be able to influence the economic activity generating the greatest risk of damaging the coral reefs.

That said, taking the opposite approach, seeking to endow the environmental institution with regulatory powers over fisheries could easily produce an important form of institutional overload: unwillingness among important member states to cede authority to the international body due to uncertainty about its priorities among the relevant concerns. In the fisheries sector, states have typically granted regional management organizations access to their national fisheries research capabilities, wide regulatory authority regarding the conduct of harvesting operations, and (frequently) the use of reporting, monitoring, and inspection procedures that enhance transparency with respect to harvesting in national and high-seas areas (Stokke 2019). Generally, the potential advantages of expanding the functional scope of an international body must be weighed against the risk that states will be less prepared to cede regulatory and enforcement authority to an international body operated or significantly influenced by sectors of government inclined to prioritize preservation over resource use.

Under such circumstances, one response strategy designed to steer a course between the reductionist peril of narrowly constrained regulation and the overload peril of a functionally broad body that lacks regulatory clout features setting up procedures in support of interplay management, allowing those who operate distinct institutions to improve the interaction among them (Stokke 2020). Such procedures may include coordinated decision making. More frequently, they feature reciprocal or one-sided adaptation (Oberthür and Stokke 2011). The NEAFC-OSPAR case exemplifies the latter option: The fisheries body decided to adapt its regulations closing certain high-seas areas for bottom trawling to the spatial boundaries defined in the environmental body's emerging network of marine 
protected areas (Kvalvik 2012). This regulatory alignment did not derive from joint decision making, which remained unacceptable to the resource management regime. Even when the national-level competence for different parts of a complex biophysical system resides with institutions with competing priorities, interplay management either by coordination or by the less ambitious means of one-sided adaptation may offer an adequate vehicle for achieving regulatory coherence.

\subsection{Bindingness/level of ambition}

Governance systems vary considerably in terms of bindingness and level of ambition or, in other words, in the extent to which substantive provisions constrain state behavior. Regarding bindingness, the provisions of a regime may vary from hard to soft, depending on whether they take the form of hard law set forth in a legally binding instrument, soft law under the terms of a ministerial declaration or similar document, or informal practices with no legal status in the ordinary sense of the term. Level of ambition refers to the breadth of the topics covered by a regime and the depth of commitments or the extent to which those commitments go beyond what the parties would do in the absence of an agreement. We can envisage a spectrum of situations with regard to bindingness and level of ambition, ranging from highly ambitious arrangements articulated in the form of hard law at one extreme to much more limited arrangements with no legal status at the other. Many of those who think about international environmental agreements take it for granted that the goal in every case is to create ambitious arrangements that are as "hard" as possible. But this assumption seems questionable. If we start with the premise that form should follow function regarding the character of governance systems, the proper approach is to address these matters caseby-case, developing arrangements likely to contribute to solving the problem(s) at hand.

Reductionism here takes the form of insisting that all the provisions of a regime should be cast as hard law, especially if coupled with an assumption that there is no need for explicit compliance mechanisms to ensure that the parties fulfill their commitments. Two major problems can lead to institutional failure in such cases. One arises from a trade-off between hardness and level of ambition. When asked to make hard-law commitments, parties to environmental agreements frequently limit both the breadth and the depth of the commitments they are willing to accept (Barrett 2007). Experience also indicates that ambitious commitments not accompanied by suitable compliance mechanisms tend to get watered down or fall by the wayside when it comes to implementation. Overload, by contrast, occurs when the agreements that establish regimes include ambitious provisions covering a wide range of issues, without any central thread to lend focus or coherence to the parties' efforts to implement individual provisions. This is a source of considerable concern in the current negotiations regarding biodiversity beyond national jurisdictions. In such cases, institutional failure often results from desultory efforts to implement specific provisions of a regime with varying degrees of success, leading to outcomes that do not add up to a coherent strategy for addressing the concern that led to the creation of the regime in the first place.

What strategies are available to avoid the perils of reductionism and overload with regard to issues concerning the form and strength of substantive provisions? Experience in the realm of international environmental governance suggests several possibilities. One strategy involves differentiating among the provisions of a regime, making some legally binding, while allowing others to take the form of much softer commitments or even voluntary pledges. An example is the 2015 Paris Climate Agreement, structured generally as a legally binding arrangement in which the Nationally Determined Contributions of the 
individual parties are treated as voluntary pledges (Cherry et al. 2014). Another strategy features opting for modest breadth and depth of commitments at the outset, coupled with procedures for raising the regime's level of participation and ambition over time. Examples here include adding protocols to a framework convention to expand the range of issues covered, as with the 1979 Convention on Long-Range Transboundary Air Pollution, or expanding the list of controlled substances, as in the case of the global 2001 Stockholm Convention on Persistent Organic Pollutants. A third strategy involves providing assistance to parties willing to participate but lacking the capacity needed to implement ambitious substantive provisions. Such assistance may involve technology transfer, training programs, or financial assistance. In every case, the challenge is to tailor the strategy so as to avoid the perils of reductionism and overload with regard to bindingness and level of ambition.

\subsection{Political context}

Efforts to craft the provisions of regimes are themselves political processes. But they occur within broader political settings that may influence the course of negotiations considerably. Relevant factors concern the extent to which the issues at hand are linked to deepseated disputes or conflicts of interest and the extent to which the political setting includes well-developed practices for cooperatively addressing needs for governance. Intense disputes and the absence of cooperative practices are likely to lead to a reductionist approach. Conversely, in examining policy arenas that deal with numerous issues, analysts often ask: Are there opportunities to make progress by broadening the agenda, adding issues and actors in efforts to address specific needs for governance? In such cases, the challenge is to avoid overload arising from outcomes of the kind referred to in domestic legislation as "Christmas tree bills" due to the convoluted nature of the deals made to build the coalitions needed to reach agreement. Often, the results are governance systems that are excessively complex and ultimately prove ineffective.

The international regime for managing the world's biggest cod stock, Northeast Arctic cod, emerged in the midst of the cold war with the dominant regime members-Norway and the Soviet Union - squarely placed on opposite sides of the East-West divide (Stokke 2012). Observers agree that the effectiveness of this regime for fisheries management derives in considerable part from the ability of those who negotiated it to avoid the reductionist trap of ignoring the larger and often conflict-ridden geopolitical context (Stokke et al. 1999; Hønneland 2012). Key components of this regime served to insulate the practical governance tasks of knowledge-building, agreed regulation, and rule enforcement at sea from contested sovereignty issues that would otherwise complicate efficient deployment of fishing capacity and responsible management measures. For instance, the elaborate procedures of the Mutual Access Agreement, allowing fishers to operate in each other's waters to optimize harvesting practices, were deliberately aimed at avoiding fisheries incidents that might escalate into diplomatic conflicts (Stokke et al. 1999). Similarly, the parties developed the Grey Zone Agreement in the 1970s, allowing parallel inspection in an area that included a disputed segment of the Barents Sea to reduce the negative effect that acceptance of fisheries enforcement by the other party would otherwise have had on each party's claim to sovereignty (Stokke and Hoel 1991). A reductionist approach to these negotiations, one that attended to the needs of fisheries management but ignored the complications arising from the East-West rivalry and competing sovereignty claims, would have had little chance of succeeding.

The opposite peril, institutional overload, looms whenever those responsible for administering an issue-specific regime assume responsibility for broader and deeper political 
problems that the institution is incapable of addressing effectively. Consider, for instance, proposals to boycott Arctic Council meetings held in Russia in order to make a firm diplomatic statement on the inadmissibility of Russia's annexation of the Crimea from Ukraine in 2014. A similar weighing of concerns was relevant when Norway considered whether its post-Crimea sanctions against Russia, which included a freeze on military cooperation, should also extend to the coast guard cooperation on fisheries inspection as well as searchand-rescue operations in the Barents Sea. Had the more extensive sanctions been chosen in these cases, they would have generated institutional overload. Relatively low-key institutions well-equipped for encouraging coordination in specific issue areas of common interest would have been burdened with a problem they were not equipped to solve. There is no basis for believing that reduced cooperation in Arctic Council activities, in the work of the Joint Norwegian-Russian Fisheries Commission, or in collaborative search-and-rescue missions in remote Arctic locations would be perceived by Russia as costly enough to induce reconsideration of its geopolitical decision regarding Crimea. Efforts to use those specialized institutions for pursuing broader security objectives would have produced overload, leading to a loss of problem-solving capacity in the issue areas involved with no significant effect on Russian behavior regarding Ukraine.

Common denominators among these efforts to find a path between reductionism and overload include the insulation of issue-specific practical cooperation of mutual interest from oscillations in the intensity of contextual disputes or conflicts and a willingness on the part of those implementing the arrangements to refrain from burdening them with broader political objectives they are ill-equipped to serve.

\section{Conclusions}

It is easy to summarize our contribution to understanding why solving environmental problems is difficult. The perils of reductionism and overload constitute pitfalls that negotiators and administrators often fall into in specific situations, even when they are aware of these dangers in general terms. Numerous risk factors can propel efforts to solve problems toward one or the other of these perils. A necessary (though not sufficient) condition to achieve success in this realm is to identify the risk factors pertinent to specific problems and to devise response strategies that provide a basis for steering a course between reductionism and overload.

There are two ways to think about the significance of this argument, one positive and the other normative. The positive perspective emphasizes the goal of explaining observed patterns of success and failure in efforts to solve international and transnational environmental problems. Many initiatives fail, but some succeed. This we explain in terms of the effects of risk factors that push negotiations toward the perils of reductionism and overload. Sometimes it is possible to steer a course that allows for safe passage between these perils. But this can occur only when the negotiators are cognizant of the pitfalls and are prepared to work together to avoid them, even while making concerted efforts to pursue their individual interests.

The normative perspective, by contrast, is a matter of offering advice to those responsible for negotiating and implementing the terms of environmental agreements. What does our analysis have to say that may be of interest to those engaged in institutional bargaining or responsible for implementing the resultant regimes? We advise these actors to develop expertise regarding the identification of risk factors and the development of response strategies. While every case is unique in some respects, it is always important to consider the 
relevance of risk factors and, we argue, to formulate response strategies that help to steer clear of the associated pitfalls of reductionism and overload.

Regime formation and implementation involve mixed-motive interactions. There is a natural tendency to approach the bargaining process as a matter of driving a hard bargain that maximizes payoffs to the individual participant. But success requires willingness and ability to cooperate to avoid the perils of reductionism and overload. The result is a delicate balancing act involving the simultaneous pursuit of common interests and conflicting interests. It is not surprising that many efforts of this sort fail, a fact that makes those that succeed all the more worthy of sustained interest.

Acknowledgements Open Access funding provided by Oslo University \& Oslo University Hospital. The work has been funded by the Research Council of Norway through POLARPROG Project No. 257614: Spatial Shifts of Marine Stocks and the Resilience of Polar Resource Management (STOCKSHIFT).

\section{Compliance with ethical standards}

Conflict of interest The authors declare that they have no conflict of interest.

Open Access This article is licensed under a Creative Commons Attribution 4.0 International License, which permits use, sharing, adaptation, distribution and reproduction in any medium or format, as long as you give appropriate credit to the original author(s) and the source, provide a link to the Creative Commons licence, and indicate if changes were made. The images or other third party material in this article are included in the article's Creative Commons licence, unless indicated otherwise in a credit line to the material. If material is not included in the article's Creative Commons licence and your intended use is not permitted by statutory regulation or exceeds the permitted use, you will need to obtain permission directly from the copyright holder. To view a copy of this licence, visit http://creativecommons.org/licenses/by/4.0/.

Open Access This article is licensed under a Creative Commons Attribution 4.0 International License, which permits use, sharing, adaptation, distribution and reproduction in any medium or format, as long as you give appropriate credit to the original author(s) and the source, provide a link to the Creative Commons licence, and indicate if changes were made. The images or other third party material in this article are included in the article's Creative Commons licence, unless indicated otherwise in a credit line to the material. If material is not included in the article's Creative Commons licence and your intended use is not permitted by statutory regulation or exceeds the permitted use, you will need to obtain permission directly from the copyright holder. To view a copy of this licence, visit http://creativecommons.org/licenses/by/4.0/.

\section{References}

Barrett, S. (2007). Why cooperate?: The incentive to supply global public goods. Oxford: Oxford University Press.

Birch, A. H. (1984). Overload, ungovernability and delegitimization. British Journal of Political Science, 14, $135-160$.

Breitmeier, H., Underdal, A., \& Young, O. R. (2011). The effectiveness of international environmental regimes: Comparing and contrasting findings from quantitative research. International Studies Review, 13(4), 579-605.

Breitmeier, H., Young, O. R., \& Zürn, M. (2006). Analyzing international environmental regimes: From case study to database. Cambridge, MA: MIT Press.

Brennan, G., \& Buchanan, J. M. (1985). The reason of rules: Constitutional political economy. Cambridge: Cambridge University Press.

Cherry, T. L., Hovi, J., \& McEvoy, M. D. (Eds.). (2014). Toward a new climate agreement: Conflict, resolution and governance. London: Routledge.

FCMA. (1976). Fishery Conservation and Management Act. PL 94-265; 90 Stat. 331; 16 USC 1801 et seq.

Hale, T., Held, D., \& Young, K. (2013). Gridlock: Why global cooperation is failing when we need it most. Cambridge: Polity Press.

Hilborn, R. (2012). Overfishing: What everyone needs to know. Oxford: Oxford University Press. 
Hønneland, G. (2012). Making international fisheries agreements work: Post-agreement bargaining in the Barents Sea. Cheltenham: Edward Elgar.

IPBES, Intergovernmental Science-Policy Platform on Biodiversity and Ecosystem Services. (2019). Summary for policymakers of the global assessment report on biodiversity and ecosystem services of the Intergovernmental Science-Policy Platform on Biodiversity and Ecosystem Services. Retrieved January 24, 2020 from https://ipbes.net/sites/default/files/ipbes_7_10_add.1_en_1.pdf.

Kvalvik, I. (2012). Managing institutional overlap in the protection of marine ecosystems on the high seas. The case of the North East Atlantic. Ocean and Coastal Management, 56, 35-43.

McLeod, K., Leslie, H., et al. (2009). Ecosystem-based management for the oceans. Washington, DC: Island Press.

MEA. (2005). Ecosystems and human well-being: Synthesis. Washington, DC: Island Press.

Miles, E. L., et al. (2002). Environmental regime effectiveness: Confronting theory with evidence. Cambridge, MA: MIT Press.

Mitchell, R. (1994). International oil pollution at sea: Environmental policy and treaty compliance. Cambridge, MA: MIT Press.

Oberthür, S., \& Stokke, O. S. (Eds.). (2011). Managing institutional complexity: regime interplay and global environmental change. Cambridge, MA: MIT Press.

OSPAR. (2007). Convention for the protection of the marine environment of the North-East Atlantic. Adopted in Paris, 22 September 1992. Latest amendment (annexes) in 2007. Retrieved January 24, 2020 from https ://www.ospar.org/convention/text.

Park, J., Conca, K., \& Finger, M. (2008). The crisis of global environmental governance. London: Routledge.

Pauly, D. (2010). 5 easy pieces: The impact of fisheries on marine ecosystems. Washington, DC: Island Press.

Schelling, T. C. (1960). The strategy of conflict. Cambridge, MA: Harvard University Press.

Sebenius, J. K. (1984). Negotiating the law of the sea. Cambridge, MA: Harvard University Press.

Speth, J. G. (2004). Red sky at morning: America and the crisis of global governance. New York: Oxford University Press.

Stokke, O. S. (2012). Disaggregating international regimes: A new approach to evaluation and comparison. Cambridge, MA: MIT Press.

Stokke, O. S. (2016). Geopolitics, governance, and arctic fisheries politics. In E. Conde \& S. S. Iglesias (Eds.), Global challenges in the Arctic region: Sovereignty, environment and geopolitical balance (pp. 170-195). London: Routledge.

Stokke, O. S. (2019). Management options for high seas fisheries: Making regime complexes more effective. In J. Caddell \& E. J. Molenaar (Eds.), Strengthening international fisheries law in an era of changing oceans (pp. 51-79). London: Hart Publishers.

Stokke, O. S. (2020). Interplay management. In F. Biermann \& R. Kim (Eds.), Architectures of earth system governance: Institutional complexity and structural transformation (pp. 165-185). Cambridge: Cambridge University Press.

Stokke, O. S., Anderson, L. G., \& Mirovitskaya, N. (1999). The Barents Sea fisheries. In O. R. Young (Ed.), The effectiveness of international environmental regimes: Causal connections and behavioral mechanisms. Cambridge, MA: MIT Press.

Stokke, O. S., \& Hoel, A. H. (1991). Splitting the gains: Political economy of the Barents Sea fisheries. Cooperation and Conflict, 26, 49-65.

Underdal, A. (2010). Complexity and challenges of long-term environmental governance. Global Environmental Change, 20, 386-393.

UNGA, United Nations General Assembly. (2017). Resolution 72/249. International legally binding instrument under the United Nations Convention on the Law of the Sea on the conservation and sustainable use of marine biological diversity of areas beyond national jurisdiction. A/RES/72/249. Retrieved January 24, 2020 from https://undocs.org/en/a/res/72/249.

van Asselt, H. (2011). Legal and political approaches in interplay management: Dealing with the fragmentation of global climate governance. In S. Oberthür \& O. S. Stokke (Eds.), Managing institutional complexity: Regime interplay and global environmental change (pp. 59-85). Cambridge, MA: MIT Press.

Young, O. R. (1994). International cooperation: Protecting the environment in a stateless society. Ithaca, NY: Cornell University Press.

Young, O. R. (2008). Building regimes for socioecological systems: Institutional diagnostics. In O. R. Young, L. King, \& H. Schroeder (Eds.), Institutions and environmental change (pp. 115-144). Cambridge: MIT Press.

Young, O. R. (2011). The effectiveness of international environmental regimes: Existing knowledge, cutting-edge themes, and research strategies. Proceedings of the National Academy of Sciences USA, 108, 19853-19860.

Young, O. R. (2017a). Governing complex systems: Social capital for the anthropocene. Cambridge: MIT Press. 
Young, O. R. (2017b). Beyond regulation: Innovative strategies for governing large complex systems. Sustainability, 9(6), 938.

Young, O. R., \& Levy, M. (1999). The effectiveness of international environmental agreements. In O. R. Young (Ed.), The effectiveness of international environmental regimes (pp. 1-32). Cambridge, MA: MIT Press.

Young, O. R., Webster, D. G., et al. (2018). Moving beyond panaceas in fisheries governance. Proceedings of the National Academy of Sciences of the United States of America, 115, 9065-9073.

Publisher's Note Springer Nature remains neutral with regard to jurisdictional claims in published maps and institutional affiliations. 